\title{
Gas Flaring: Carbon dioxide Contribution to Global Warming
}

\section{*AMAECHI, CHIKA FLOYD; BIOSE EKENE}

\author{
Department of Environmental Management and Toxicology, \\ Faculty of Life Sciences, University of Benin, Benin City \\ *Corresponding author email: chika.amaechi@uniben.edu
}

\begin{abstract}
Within 1950 - 2004 the earth recorded a considerable increase in its average ambient temperature. This was however due to increase in anthropogenic carbon dioxide emissions resulting from high consumption of fossil fuels. Flaring been a source of anthropogenic carbon dioxide, is a concern to skeptics and local oil producing communities as a significant contributor to global warming, environmental degradation, health risk and economic loss. The purpose of the study was to ascertain the impacts of gas flaring on global warming and the local oil producing communities. The study adopted the quantitative and qualitative methods of analysis. The quantitative method involved using results complied by researchers of the Carbon Dioxide Information and Analysis Center showing the total anthropogenic carbon dioxide emissions (1950 -2004) from various sources to determine the impact carbon dioxide from flaring has had on global warming. The determination was done using a computer software (excel). The qualitative method on the other hand involved the use of case study literatures to examine and review the impacts gas flaring has on the local oil producing communities. The quantitative method of analysis showed that carbon dioxide from gas flaring constitute $1 \%$ of the total anthropogenic carbon dioxide which was considered insignificant, whilst the case study review of the qualitative method showed that gas flaring cause environmental degradation, health risks and constitute financial loss to the local oil producing communities. The research went ahead to refute the argument that gas flaring causes global warming, however acknowledging that it causes environmental degradation, health risks and economic loss to the local oil producing communities. (C) JASEM http://dx.doi.org/10.4314/jasem.v20i2.11
\end{abstract}

\section{Introduction}

Global warming is the increase in the average measured temperature of the earth's near-surface air and oceans since the mid-twentieth century, and its projected continuation (IPCC, 2001). According to the Intergovernmental Panel on Climate Change (IPCC), the average global air temperature near the earth's surface has increased by $0.74 \pm 0.18{ }^{\circ} \mathrm{C}(1.33 \pm$ $0.32^{\circ} \mathrm{F}$ ) during the hundred years ending in 2004 and most of the observed increase in average atmospheric greenhouse concentration since the mid-twentieth century is very likely due to the observed increase in anthropogenic (man-made) greenhouse gas concentrations via an enhanced greenhouse effect (IPCC, 2007). Natural phenomena such as solar variation combined with volcanoes probably had a small warming effect from pre-industrial times to 1950 and a small cooling effect from 1950 onward (Hegerl et al., 2007; Ammann et al., 2007).

The IPCC says the warming of the earth since the 1950 's is due to increased anthropogenic emissions of greenhouse gases from high consumption of fossil fuels, and the greenhouse gases considered to be contributing to these rising temperatures include carbon dioxide $\left(\mathrm{CO}_{2}\right)$, methane $\left(\mathrm{CH}_{4}\right)$ and nitrous oxide $\left(\mathrm{N}_{2} \mathrm{O}\right)$, and three fluorinated industrial gases; hydrofluorocarbons (HFCs), perfluorocarbons (PFCs) and sulphur hexafluoride $\left(\mathrm{SF}_{6}\right)$ (IPCC, 2001). Although of these, methane is potentially the most dangerous, carbon dioxide is the primary cause of global rising temperatures contributing about $80 \%$ of man made greenhouse gases (World Bank, 2007; Marland et al., 2005). According to the researchers of the Carbon Dioxide Information and Analysis Center, anthropogenic carbon dioxide emissions results from burning of fossil fuels (liquid, solid and gas), cement production and flaring (Marland et al.,1998).

Whilst burning of fossil fuels and cement production contributes to total anthropogenic carbon dioxide emissions resulting to global warming, attention will be devoted to gas flaring for the purpose of this study.

Scientific studies conducted by Ishisone (2003); Grevet (2007); the World Bank and; researchers of the IPCC all sugggest that gas flaring contributes to global warming (Ishisone, 2003; Grevet, 2007; World Bank, 2008; IPCC, 2007). In addition, the World Bank estimates that the annual volume of flared and vented natural gas is more than 150 billion cubic meters, or approximately the combined annual gas consumption 
of Germany and France (World Bank, 2008). Greenhouse gas emissions from flaring are also about 13 percent of committed emission reductions by developed countries under the Kyoto Protocol (World Bank, 2002). For the past 20 years, global flaring levels have remained virtually constant despite successful efforts by individual governments and companies to use the associated gas and thereby reduce flaring (World Bank, 2007).Concerns about global rising temperature and the challenges and risks flaring of gas poses will require sustained efforts to develop understanding and effective solutions while at the same time meeting the growing needs of society for energy. Addressing these risks requires appropriate actions now, recognising that near-term actions alone cannot address the long-term, global challenges and risks of climate change.

Meeting global energy demand whilst limiting or reducing carbon dioxide emissions presents an enormous challenge. Energy outlooks show that between now and 2030 the bulk of the increase in energy demand will be met by fossil fuels (IPCC, 2001). Renewable energy sources, such as wind and solar, will enjoy high growth rates. However, they start from a very low level and will have a limited impact in this timeframe. Greenhouse gas emissions have grown, and are projected to continue to grow, along with worldwide economic activity and energy demand. Making deep reductions in global greenhouse gas emissions would entail significant changes in the way society produces and uses energy, necessitating the development and deployment of energy efficient and low-emission technologies for all major sectors of the economy and for all major regions of the world. The oil and gas industry realises major challenges and opportunities lie ahead in addressing risks of global warming. These include taking actions now to reduce emissions, providing new more powerful energy options, and gaining a clearer understanding to better guide society's response. These efforts will need to be undertaken while continuing to provide energy for socioeconomic needs.

Aim and Objectives of Study: This dissertation aims to assess the contribution of gas flaring to global warming from 1950 - 2004. The assessment is characterised by the analysis of anthropogenic carbon dioxide emissions of gas flaring from 1950 -2004 and outcomes of previous scientific studies.

The objectives of this research involves analysing statistics of anthropogenic carbon dioxide emissions from 1950 - 2004 compiled by Marland, G, Andres, B and Boden, T. of the Carbon Dioxide Information and Analysis Center (CDIAC) and augmenting it with outcomes of previously published scientific studies (including those by Gray in 1998, the World Bank in 2008, IPCC in 2007 and Grevet in 2007). The assessment of gas flaring contribution to global warming are expressed in terms of: (1) the percentage carbon dioxide from gas flaring contributed to the cumulative anthropogenic carbon dioxide emission from 1950 -2004; (2) concentration in part per million (ppm) carbon dioxide from gas flaring has contributed to anthropogenic carbon dioxide concentration from 1950 -2004 and; 3) the temperature carbon dioxide from gas flaring contributed to the average global temperature from $1950-2004$.

\section{MATERIALS AND METHOD}

The research relied primarily on a review of a range of secondary sources. This was augmented by some analysis of quantitative data on flaring and emissions of carbon dioxide. This is because quantitative approach is specifically effective in obtaining annual trends in amounts of gases flared and comparing flaring rates among countries. It is the most suitable method for achieving the research aim because it produces accurate results. This method was adopted also because of its reliability and the fact that results derived are from outcomes of previous studies. Quantitative approach was adopted for this study because it aims to explore issues in-depth, rather than simply describing them at a superficial level in other words it gives detailed descriptions and explanations of the phenomenon (Eves and Dervisi, 2005).

For the purpose of achieving the research aim, the researcher sorted and analysed data on global anthropogenic carbon dioxide emissions (as $\mathrm{CO} 2$ is the primary cause of global warming) compiled by researchers in the Carbon Dioxide Information and Analysis Center on carbon dioxide emissions from 1751 - 2004 though the study focuses on carbon dioxide emissions from 1950 - 2004, and outcomes of previously conducted studies of the IPCC; The World Bank and; Gray, M.

In order to find out the most reliable database on anthropogenic carbon dioxide emission, the researcher sorted the databases of the two institutions that compile anthropogenic emissions to understand why the different databases show different data.The first database reviewed by the researcher was that of the Energy Information Administration (EIA, Appendix 2 ). In this database, the gas flaring emission was obtained by comparing the world carbon dioxide emissions from the consumption and flaring of natural gas, and the world carbon dioxide emissions from the consumption of natural gas. 
Whilst the second database reviewed was that of the Carbon Dioxide Information Analysis Centre (CDIAC, Appendix3). Here, the gas flaring emission was given. The CDIAC's database was relevant because it dates back to 1950, unlike the EIA's database which started from 1980. Moreover, all flared gasemissions since 1950 were recorded, from the production of cement, crude oil, coal andnatural gas.

In addition, the CDIAC's database contained global annual estimates of $\mathrm{CO} 2$ emissions resulting from gas flaring from all sources from 1950 - 2004, whilst the EIA's database results from gas flaring in oil fields and in some gas plants. EIA has no authority to require data from the plants. The database only contains the data that was provided to them (EIA, Appendix 2). Moreover, nowadays, a great part of flared gas is emitted by Liquefaction Natural Gas (LNG) plants (F.R. Mouton, World Bank, Appendix 1). The LNG production started in 1969 . These led to the researcher's adoption of the CDIAC database of carbon dioxide emissions. The methods of data collection by the researchers in the Carbon Dioxide Information and Analysis Center are as follows;

Method of Data collection of Compiled Global Anthropogenic Carbondioxide Emissions (Period of Record 1950-2004), Publications containing historical energy statistics made it possible for the researchers (Marland et al., 2007) to estimate fossil fuel $\mathrm{CO}_{2}$ emissions back to 1751. Etemad et al (1991) published a summary compilation that tabulates coal, brown coal, peat, and crude oil production by nation and year.
Footnotes in the Etemadet al (1991) publication extended the energy statistics time series back to 1751 . Summary compilations of fossil fuel trade were published by Mitchell (1983, 1992, 1993, and 1995). Mitchell's work tabulates solid and liquid fuel imports and exports by nation and year. These pre-1950 production and trade data were digitised and $\mathrm{CO}_{2}$ emission calculations were made using questionnaires and estimates from computer simulation as stated in Marland and Rotty (1984) and Boden et al., (1995).

The 1950 to present $\mathrm{CO}_{2}$ emission estimates are derived primarily from energy statistics published by the United Nations (2006). The energy statistics were compiled primarily from annual questionnaires distributed by the U.N. Statistical Office and supplemented by official national statistical publications. As stated in the introduction of the 'Statistical Yearbook', in a few cases, official sources were supplemented by other sources and estimates. These were subjected to professional scrutiny and debate and are consistent with other independent sources. Data from the U.S. Department of Interior's Geological Survey (USGS, 2007) were used to estimate $\mathrm{CO}_{2}$ emitted during cement production. Values for emissions from gas flaring were derived primarily from U.N. data but were supplemented with data from the U.S. Department of Energy's Energy Information Administration (1994), Rotty (1974), and data provided by Marland (1998). Table 8 shows anthropogenic carbon dioxide emissions as compiled by the researchers.

Table 1: Compiled Results Of Global Carbon Dioxide Emissions From Fossil Fuel Burning (Gas, Liquids And Solids), Cement Production And Gas Flaring (1950 - 2004) (Source; (Marland, G , Andres, B and Boden, T , 2007). All emission estimates are expressed in million metric tonnes of carbon dioxide.

\begin{tabular}{|l|l|l|l|l|l|l|}
\hline YEAR & TOTAL & GAS & LIQUIDS & SOLIDS & $\begin{array}{l}\text { CEMENT } \\
\text { PRODUCTION }\end{array}$ & FLARING \\
\hline 1950 & 1630 & 97 & 423 & 1070 & 18 & 23 \\
\hline 1951 & 1767 & 115 & 479 & 1129 & 20 & 24 \\
\hline 1952 & 1795 & 124 & 504 & 1119 & 22 & 26 \\
\hline 1953 & 1841 & 131 & 533 & 1125 & 24 & 27 \\
\hline 1954 & 1865 & 138 & 557 & 1116 & 27 & 27 \\
\hline 1955 & 2043 & 150 & 625 & 1208 & 30 & 31 \\
\hline 1956 & 2177 & 161 & 679 & 1273 & 32 & 32 \\
\hline 1957 & 2270 & 178 & 714 & 1309 & 34 & 35 \\
\hline 1958 & 2330 & 192 & 731 & 1336 & 36 & 35 \\
\hline 1959 & 2462 & 214 & 789 & 1382 & 40 & 36 \\
\hline 1960 & 2577 & 235 & 849 & 1410 & 43 & 39 \\
\hline 1961 & 2594 & 254 & 904 & 1349 & 45 & 42 \\
\hline 1962 & 2700 & 277 & 980 & 1351 & 49 & 44 \\
\hline 1963 & 2847 & 300 & 1052 & 1396 & 51 & 47 \\
\hline 1964 & 3008 & 328 & 1137 & 1435 & 57 & 51 \\
\hline 1965 & 3145 & 351 & 1219 & 1460 & 59 & 55 \\
\hline 1966 & 3305 & 380 & 1323 & 1478 & 63 & 60 \\
\hline 1967 & 3411 & 410 & 1423 & 1448 & 65 & 73 \\
\hline 1968 & 3588 & 446 & 1551 & 1448 & 70 & \\
\hline
\end{tabular}




\begin{tabular}{|c|c|c|c|c|c|c|}
\hline 1969 & 3800 & 487 & 1673 & 1486 & 74 & 80 \\
\hline 1970 & 4077 & 516 & 1839 & 1557 & 78 & 87 \\
\hline 1971 & 4231 & 554 & 1946 & 1559 & 84 & 88 \\
\hline 1972 & 4399 & 583 & 2056 & 1576 & 89 & 94 \\
\hline 1973 & 4635 & 608 & 2240 & 1582 & 95 & 110 \\
\hline 1974 & 4644 & 618 & 2245 & 1579 & 96 & 107 \\
\hline 1975 & 4615 & 623 & 2132 & 1673 & 95 & 92 \\
\hline 1976 & 4884 & 650 & 2313 & 1710 & 103 & 108 \\
\hline 1977 & 5035 & 649 & 2401 & 1773 & 108 & 104 \\
\hline 1978 & 5107 & 677 & 2406 & 1802 & 116 & 106 \\
\hline 1979 & 5403 & 719 & 2562 & 1905 & 119 & 98 \\
\hline 1980 & 5348 & 740 & 2445 & 1957 & 120 & 86 \\
\hline 1981 & 5186 & 756 & 2317 & 1928 & 121 & 64 \\
\hline 1982 & 5144 & 746 & 2219 & 1994 & 121 & 64 \\
\hline 1983 & 5126 & 745 & 2202 & 1996 & 125 & 58 \\
\hline 1984 & 5308 & 808 & 2229 & 2092 & 128 & 51 \\
\hline 1985 & 5464 & 836 & 2209 & 2239 & 131 & 49 \\
\hline 1986 & 5629 & 830 & 2319 & 2297 & 137 & 46 \\
\hline 1987 & 5762 & 893 & 2333 & 2349 & 143 & 44 \\
\hline 1988 & 5992 & 936 & 2441 & 2412 & 152 & 50 \\
\hline 1989 & 6106 & 972 & 2489 & 2447 & 156 & 41 \\
\hline 1990 & 6196 & 1026 & 2588 & 2385 & 157 & 40 \\
\hline 1991 & 6312 & 1086 & 2706 & 2315 & 161 & 44 \\
\hline 1992 & 6187 & 1101 & 2593 & 2291 & 167 & 35 \\
\hline 1993 & 6203 & 1119 & 2640 & 2232 & 176 & 36 \\
\hline 1994 & 6344 & 1132 & 2684 & 2306 & 186 & 37 \\
\hline 1995 & 6487 & 1153 & 2719 & 2383 & 196 & 36 \\
\hline 1996 & 6649 & 1208 & 2778 & 2424 & 203 & 36 \\
\hline 1997 & 6840 & 1211 & 2950 & 2433 & 209 & 37 \\
\hline 1998 & 6788 & 1245 & 2983 & 2320 & 209 & 32 \\
\hline 1999 & 6804 & 1274 & 2966 & 2316 & 217 & 31 \\
\hline 2000 & 6981 & 1309 & 3069 & 2335 & 226 & 42 \\
\hline 2001 & 7116 & 1324 & 3069 & 2450 & 237 & 36 \\
\hline 2002 & 7167 & 1366 & 3032 & 2475 & 252 & 42 \\
\hline 2003 & 7504 & 1400 & 3151 & 2636 & 276 & 41 \\
\hline 2004 & 7910 & 1434 & 3289 & 2838 & 298 & 51 \\
\hline
\end{tabular}

The outcomes of the following previous studies together with above anthropogenic carbon dioxide emissions statistics was used by the researcher to assess gas flaring contribution to global warming.

Table 2: PREVIOUS STUDIES

\begin{tabular}{|l|l|l|l|l|}
\hline AUTHORS & DATE & STUDY & OUTCOMES & \\
\hline Gray, M & 1998 & $\begin{array}{l}\text { How much atmospheric } \\
\text { carbon dioxide is } \\
\text { anthropogenic? }\end{array}$ & $\begin{array}{l}\text { One billion tones of carbon } \\
\text { dioxide emitted increases the } \\
\text { atmospheric carbon dioxide } \\
\text { concentration by 0.25pm and } \\
\text { the atmospheric carbon } \\
\text { dioxide concentration at 1950 } \\
\text { was 310ppm. }\end{array}$ & \\
\hline World Bank & 2008 & Gas flaring and its effects & $\begin{array}{l}\text { The temperature of the earth } \\
\text { has increased by 0.7 degrees } \\
\text { from 1950 to 2004 and Gas } \\
\text { flaring contributes to global } \\
\text { warming. }\end{array}$ & \\
\hline IPCC & 2007 & $\begin{array}{l}\text { Global warming and climate } \\
\text { change }\end{array}$ & $\begin{array}{l}\text { The average temperature of } \\
\text { the earth at 1950 is 13.7 } \\
\text { degrees and 14.4 degrees at } \\
\text { 2004 }\end{array}$ & \\
\hline Grevet, B & 2007 & $\begin{array}{l}\text { Does gas flaring contributes to } \\
\text { global warming }\end{array}$ & $\begin{array}{l}\text { Gas flaring contributes to } \\
\text { global warming }\end{array}$ & \\
\hline
\end{tabular}

Procedure/Approach to Method Adopted: The researcher started his analysis by analysing for the annual trend of global carbon emissions and that of the various anthropogenic carbon sources. He went on to analyse the percentage annual trend of the various anthropogenic carbon sources to global annual emissions. He continued by analysing the percentage 
annual trend of only gas flaring to that of global annual emissions.

To assess the contribution of gas flaring to global warming from 1950 - 2004 in terms of percentage, concentration and temperature, the researcher analysed the emission statistics of anthropogenic carbon dioxide emissions from 1950 - 2004 together with outcomes of Gray's 1998 study, the World Bank study of 2008 and the IPCC study of 2007. The researcher achieved these by first determining the cumulative carbon emission from 1950 - 2004 of the various anthropogenic sources which he used to determine the percentages the anthropogenic carbon sources contribute to the overall anthropogenic carbon emissions. This was done to ascertain the percentage carbon dioxide from gas flaring contributed to the overall anthropogenic carbon dioxide emissions.

Thereafter the researcher used the percentage carbon dioxide gas flaring contributed to determine the concentration in parts per million (ppm) flaring has contributed to total anthropogenic carbon dioxide concentration, using outcomes of Gray's (1998) study 'How much of the Atmospheric carbon dioxide is Anthropogenic" which showed that for every one billion tonnes of carbon emitted there is a $0.25 \mathrm{ppm}$ increase in the concentration of atmospheric carbon dioxide. After determining the concentration flaring contributes the researcher proceeded to assessing the average temperature increase contributed by gas flaring to global warming given the average

\section{RESULTS AND DISCUSSION}

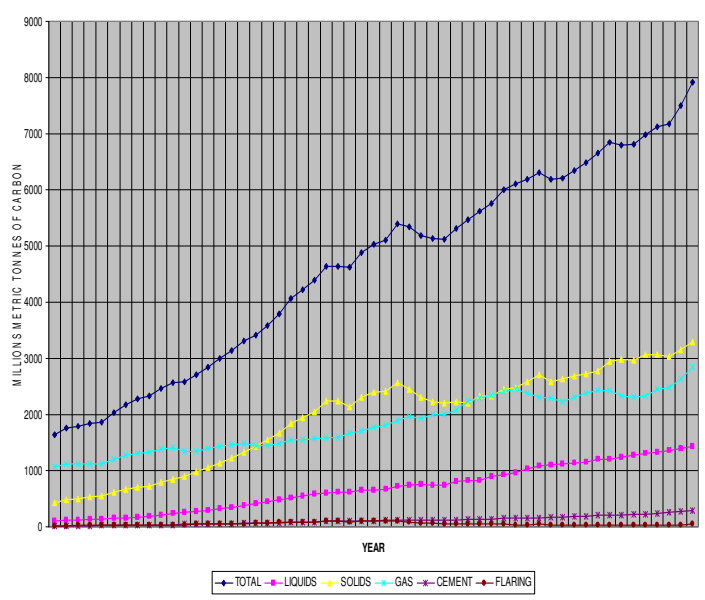

Fig 1: Global Annual Emission and Annual Emission from Anthropogenic Sources temperature increase from 1950 - 2004 using outcomes from the World Bank study and the IPCC study.

Ethical Consideration: The research has in no way breached the policy of the International Research Center on ethical standards. In the course of the research the researcher did not compromise the results of the authors of the various literatures in other to achieve the aim of the research. The researcher also followed clear and analytical procedures whilst analysing data towards achieving the research aim.

Problems Encountered: The problems encountered by the researcher during the course of this study include improper explanation of statistical details of anthropogenic carbon dioxide emissions from various sources by authors of the literatures. Another shortcoming was that the actual global atmospheric temperature and concentration was not provided by authors of the literatures. Also, literatures on case study posed difficult problems because they were not readily available at the beginning of this research thereby causing delays in the completion of the research.

Limitation of Method Adopted: Critics have said that this method of analysis is not representative enough and that it is too narrow on a general application. However, in general terms the specific benefits of this method far out weighs its weakness especially when data used are of high integrity (Tellis, 1997).

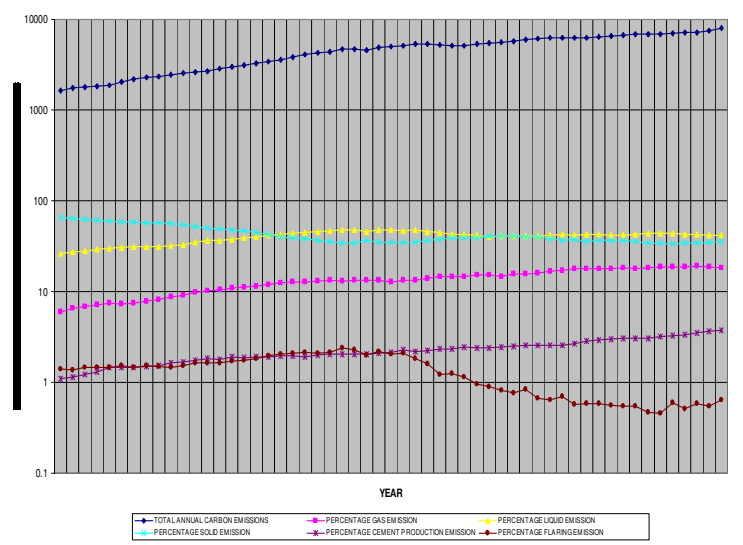

Fig 2 (Logarithm chart): Percentage Annual Emissions of Anthropogenic Sources to Global Annual Carbon Emissions 


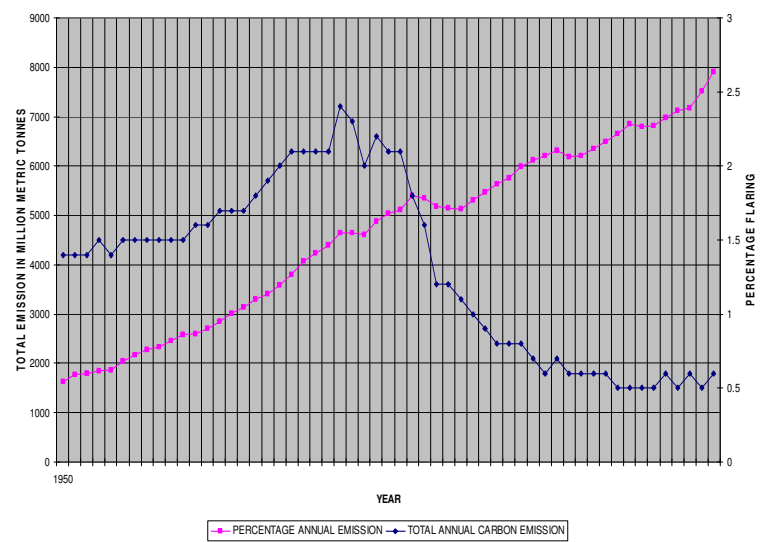

Fig 3: Percentage Annual Flaring Emission and Global Annual Carbonemission

Table 3: Cumulative contributions of various Anthropogenic Carbon Dioxide Sources to Global Warming from $1950-2004$

\begin{tabular}{|c|c|c|c|c|c|c|}
\hline & GAS & LIQUIDS & SOLIDS & CEMENT & FLARING & TOTAL \\
\hline \begin{tabular}{lr}
\multicolumn{2}{l}{$\begin{array}{l}\mathrm{CO} 2 \\
\text { EMISSIONS (millions } \\
\text { tones) }\end{array}$}
\end{tabular} & 37815 & 106705 & 100894 & 6346 & 2976 & 254738 \\
\hline PERCENTAGE $(\%)$ & 14.9 & 41.9 & 39.6 & 2.44 & 1.16 & 100 \\
\hline $\begin{array}{|ll|}\text { CENTRATION } & \text { (ppm) } \\
\end{array}$ & 9.45 & 26.68 & 25.22 & 1.58 & 0.75 & 63.68 \\
\hline TEMPERATURE ( C) & 0.103 & 0.29 & 0.28 & 0.017 & 0.008 & 0.7 \\
\hline
\end{tabular}

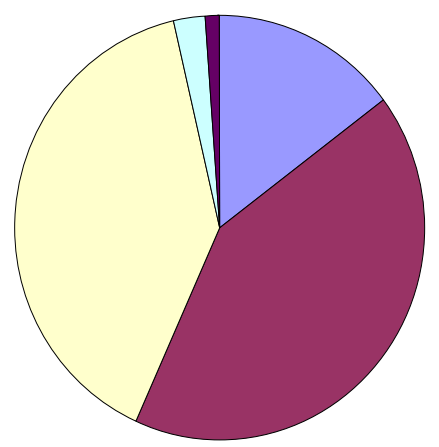

\begin{tabular}{r|}
\hline 9 \\
02 \\
03 \\
04 \\
-5 \\
\hline
\end{tabular}

Fig 4: Pie Chart representation of table 10 (cumulative Contributions of various Anthropogenic Carbon Dioxide Sources to Global Warming from 1950 - 2004)

Analysis of Results: From the analysis of Table 1 and outcomes in table 2 'previous studies', figures 1, 2, 3, 4 and table 3 were established. Figure 1 is a graphical representation showing the trend of global annual carbon dioxide emission and annual carbon dioxide emissions from various anthropogenic sources (liquids, solid and gas cement production and flaring) from 1950 - 2004. All estimates are expressed in millions metric tonnes of carbon. The representation shows that from 1950 - 2004 carbon released into the atmosphere from the consumption of fossil fuels (liquid, solid and gas), cement production and flaring amounted to roughly 254 billion tonnes (also see table 3 ) and half of these emissions have occurred since the mid 1970s. The 2004 global fossil-fuel $\mathrm{CO}_{2}$ emission estimate were 7910 million metric tonnes of carbon, representing an all-time high and a 5.4\% increase from 2003.

Globally, liquid and solid fuels accounted for $77.5 \%$ of the emissions from fossil-fuel burning in 2004. Combustion of gas fuels (e.g., natural gas) accounted for $18.1 \%$ (1434 million metric tonnes of carbon) of the total emissions from fossil fuels in 2004 and reflects a gradually increasing global utilisation of natural gas. Emissions from cement production (298 million metric tonnes of carbon in 2004) have more than doubled since the mid 1970s and now represent $3.8 \%$ of global $\mathrm{CO}_{2}$ releases from fossil-fuel burning and cement production. Gas flaring, which accounted 
for roughly $2 \%$ of global emissions during the 1970 s, now accounted for less than $1 \%$ of global fossil-fuel releases (see figure 11 and appendix 1). On the other hand the graphical representation also shows that although carbon dioxide emissions produced by solid fuel consumption were highest of other anthropogenic sources during the 1950's and 60's, consumption of liquid fuels are at its highest in recent times making it the highest emitter of carbon dioxide. Generally, figure 1 shows a steady increase in carbon dioxide emissions from fossil fuels consumption and cement production and a decline in gas flaring emission since its peak in the 1970's with the year 1999 having the lowest emission levels since 1955.

Figure 2 is a logarithm chart although similar to figure 10 in emission trends; it however shows the annual percentage trend of each anthropogenic source to the global annual carbon dioxide emission.

Figure 3 is a graphical representation showing the percentage carbon dioxide gas flaring contributes to the global annual carbon dioxide emission from 1950 -2004. It shows that whilst annual total anthropogenic carbon dioxide emissions is on the increase, percentage annual carbon dioxide emissions of gas flaring is declining. The graph also shows that there was a linear trend of emissions between 1950's 1970 's, this was as a results of high consumption of fossil fuels needed for industrialisation. On the other hand it shows that the 1980's up till 1999 saw a steady decline in the carbon dioxide emissions from gas flaring. This decline resulted from high utilisation of gas for various other purposes, for example electricity (Petrosyan, 2005). The year 2000 - 2004 saw an increase in carbon dioxide emission of gas flaring, though it can not be said to be significant, it was as a result of rapid industrialisation and consumption of fossil fuels by the East (China and India). The graph reveals that carbon dioxide from gas flaring was at its peak in the 1970's accounting for more than half of all gas flared from 1950 - 2004. The 1950's - 1970's showed higher emissions than present day emissions not because there was more industrialisation then than now, but because technology has advanced resulting in significant reduction of gas flared (OGP, 2000). This supports Ishisone (2003) environmental study which showed that gas stacks without scrubbers emitted significant amount of carbon than those equipped with gas scrubbers. The graph also shows that the 1970's recorded the highest carbon dioxide emissions with a mean annual emission of 99.4 millions metric tonnes.

Table 3 and Figure 4 shows that of the cumulative anthropogenic carbon dioxide emissions from 1950 -
2004, carbon dioxide emissions from gas flaring was 2.9 billion tonnes contributing $1.16 \%(0.75 \mathrm{ppm})$ and 0.008 degrees to global warming; natural gas which accounts for 37.8 billion tonnes contributed $14.9 \%$ (9.45ppm) and 0.103 degrees to global warming; liquid fuels accounted for 106.7 billion tonnes contributing $41.9 \%(26.68 \mathrm{ppm})$ and 0.29 degrees to global warming; solid fuels and cement production contributed 100.8 billion tonnes $(39.6 \%$ (25.22ppm) and 0.28 degrees) and 6.3 billion tonnes $(2.44 \%$ (1.58ppm) and 0.017 degrees) respectively. Cumulatively, all the anthropogenic sources contributed 254738 million tonnes of carbon to atmospheric carbon dioxide and 63.68ppm to total atmospheric carbon dioxide concentration from 1950 - 2004.

From the above analysis, it can be said that the probability of flaring contributing to global warming is $1 \%(0.0116)$ and that the probability of it not contributing is $99 \%(0.99)$. It can also be said that carbon dioxide footprints from the burning of liquid fuels $(41.9 \%)$, solid fuels $(39.6 \%)$ and natural gas $(14.9 \%)$ contributed significantly to the total anthropogenic carbon dioxide emissions within the period under review.

Outcomes of this study supports those of previous studies that gas flaring contributes to global warming (Grevet, 2007; IPCC, 2007; World Bank, 2008) but it also suggests that although gas flaring contributes to global warming its contribution is insignificant

However, gas flaring contributes significantly to local air pollution, acid rain and associated health risks to local oil producing communities. According to a study by Leahey and Preston, the combustion processes with complete combustion create relatively innocuous gases such as carbon dioxide and water. However, because the flaring efficiency depends on wind speeds, stack exit velocity, stoichiometric mixing ratios, and heating value, the flaring in reality is rarely successful in the achievement of complete combustion (Leahey and Preston, 2001). Although the results of the study do not show that gas flaring produces a significant amounts of carbon dioxide, the flaring process with incomplete combustion emits a variety of compounds, including methane, propane, and hazardous air pollution substances such as volatile organic compounds (VOCs), polycyclic aromatic hydrocarbons (PAHs), and soot (Kindzierski, 2000).

The effects gas flaring has on human health as shown in a study by the Alberta Research Council, are all related to the exposure to hazardous air pollutants emitted during incomplete combustion of gas flare. 
These pollutants are associated with a variety of adverse health impacts, including cancer and noncancer, neurological, reproductive, and development effects (Kindzierski, 2000). Also, the health study conducted by Dr. Cheryl Waldner presents concrete evidence that flaring, particularly of sour gas, can have a negative impact on animals and their reproduction rates if they are exposed to the emissions (Waldner, 1996).

In addition to these localised pollution hazards, it must be remembered that any gas flared denies its use as a fuel, i.e, economic loss. An economic study conducted by Ishisone using the 2004 price of carbon dioxide per tonne showed that if the SPDC (Shell Petroleum Development Company) continues to flare in the next 15 years in Imiringi, Nigeriawill lose \$ 63.4 million (valuing $\mathrm{CO}_{2}$ at $\$ 0$ per tonne) to $\$ 140.9$ million ( $\$ 20$ per tonne $\mathrm{CO}_{2}$ ). Likewise, if the AGIP does not stop flaring over the next 15 years in Obama, Nigeria also loses a huge amount of money, ranging from $\$ 126.7$ million ( $\$ 0$ per tonne $\mathrm{CO}_{2}$ ) to 281.9 million $(\$ 20$ per tonne $\mathrm{CO}_{2}$ ).

Conclusions: Flaring is an unavoidable process primarily for reasons of safety. In some cases, some gas may need to be flared at the production site; in other cases for reasons that are often a combination of geography and availability of customers for gas as well as local political factors.

Industry continues to seek opportunities to reduce the amount of gas being flared. As an example, since the mid-1970's, the amount of carbon dioxide emitted due to flaring has nearly halved, and further reductions continue to be sought. New technologies are being developed to assist in the commercialisation of associated gas reserves. Operation, maintenance and design of flare systems are improving. New ways of storing associated gas are being investigated.

Whilst recognising the need for these improvements, it is important to note that outcomes of this study are consistent with those of previous studies that suggests gas flaring contributes to global warming, however this study shows that flaring contributed only 0.008 degrees to average global temperature and $1.16 \%$ (0.75ppm) to anthropogenic carbon dioxide emissions from 1950 - 2004, which makes it relatively an insignificant contributor to anthropogenic greenhouse gas-related emissions that results to global rising temperature (global warming). But on the other hand, it finds gas flaring contribution to local air pollution, associated health risks, acid rain and economic loss to local oil producing significant.

In addition, this study found the consumption of liquid fuels, solid fuels and natural gas high thus the emission of significant amounts of carbon dioxide responsible for the increased global average ambient temperature between 1950 and 2004. This calls for efforts from governments and industry to development new policies and strategies to curtail the high consumption of these fuels by way of providing alternative energy and investing in the development of new technologies.

With regards to gas flaring an important point to be drawn from the information presented in this dissertation is the need for industry to be able to choose from among a variety of creative and common sense approaches to address flaring concerns in specific operations. Whether with respect to selecting among reduction technologies, choosing between flaring or venting, utilisation strategies or maintaining a balance between climate change and other environmental concerns, regulatory frameworks need to allow for best practicable choices to be made, rather than mandating a specific solution. No single approach will necessarily be appropriate for all projects or locations.

The intrinsic value of the gas being flared motivates the industry to manage the issue well. Government regulatory policy needs to be sufficiently flexible to facilitate the choice of the management approachmost appropriate for the project and the situation.

Limitations of Study: The main uncertainty results from the incomplete available data. Marland and Rotty (1984) estimated that the uncertainty of the annual global $\mathrm{CO} 2$ emission is 6 to $10 \%$. It is mainly due to a lack of information provided by countries such as Russia. Moreover, the data comes mainly from the oil field, neglecting the other sources, and most of operators in oil field are not required to meter gas that is vented or flared. Hence, we can understand how incomplete the database may be. On the other hand, the database does not distinguish between vented and flared gas. The vented gas is far less recorded than the flared gas. It is taken into account in the database, when it is known, the rest of the time, it is not included.

\section{REFERENCES}

Ammann, C. M., Joos, F., Schimel, S. D., OttoBliesner, B. L. and Tomas, R. A. (2007).Solar influence on climate during the past millennium: Results from ransient simulations with the NCAR Climate Simulation Model, Academy of Sciences of the United States of AmericaVol 104 (10), pp. 3713-3718. 
Eves, A. and Dervisi, P. (2005). Experiences of the implementation and operation of hazard analysis critical control points in the food service sector, International Journal of Hospitality and Management, Vol 24 (1), pp. 3-19.

Gervet, B. (2007). Gas Flaring Emission Contributes to Global Warming, Science, Vol 34 (4), pp. 34 -38 .

Hegerl, G.C., Zwiers, F. W., Braconnot, P., Gillett, N. P., Luo, Y., Marengo Orsini, J. A., Nicholls, N., Penner J. E. and Stott, P. A. (2007). Understanding and Attributing Climate Change, Cambridge University Press, Cambridge, United Kingdom.

Harding, G. W. (1998). How Much of Atmospheric Carbon Dioxide Accumulation Is Anthropogenic? Journal of Air \& Waste Management, Association, Vol 23 , pp. 9-15.

IPCC . (2001). Third Assessment Report: Summary for Policymakers, Intergovernmental Panel on Climate Change (IPCC), Geneva.

IPCC. (2007). Climate Change 2007: The Physical Science Basis. Contribution of Working Group I to the Fourth Assessment Report of the Intergovernmental Panel on Climate Change, IPCC, Geneva.

Ishisone, M. (2003). Gas Flaring in the Niger Delta: the Potential Benefits of its Reduction on the Local Economy and Environment [online], Available internet: http://istsocrates.berkeley.edu/ es196/projects/2004final/ Ishone.pdf Accessed on 07/07/2008

Kindzierski, W.D. (2000). Importance of human environmental exporsure to hazardous air pollutants from gas flares, Environmental Reviews Vol 8, pp. 41-62.

Leahey, D.M. and Preston, K. (2001). Theoretical and observational assessments of flare efficiencies, Journal of the Air and Waste Management Association, Vol 51, pp. 1610-1616

Marland, G., Boden, T. A. and Andres, R. J. (2005).Global, Regional, and National $\mathrm{CO}_{2}$ Emissions. In Trends: A Compendium of Data on Global Change, Carbon Dioxide Information Analysis Center, Oak Ridge National Laboratory,
U.S. Department of Energy, Oak Ridge, Tennessee.

Marland, G., Andres, R. J., Boden, T. A, Johnston, C. and Brenkert, A. (1995) Global, Regional, and National CO2 Emissions Estimates from Fossil Fuel Burning, Cement Production, and Gas Flaring, U.S. Department of Energy, Carbon Dioxide Information Analysis Centre, Oak Ridge National Laboratory, Oak Ridge, Tenn., U.S.A.

Tellis, W. (1997). Introduction to case study. The Qualitative Report, Volume 3,(2)

Waldner, C. (1996). Beef Herd Health and Productivity and Exposure and Exposure to the Petroleum Industry in West-Central Alberta, University of Saskatchewan, Alberta.

Waldner, C. L., Ribble, C. S. , Janzen, E. D. and Campbell, J. R. (1991). Association between total sulfation, hydrogen sulfide deposition, and beefcattle breeding outcomes in Western Canada, Preventive Veterinary Medicine, Vol 50(July), pp.19-33.

World Bank Group. (2002). Global Gas Flaring Reduction Initiative Launched As Public-Private Partnership [online], Available internet: www.ifc.org/ogc.global gas.htm Accessed on 13 July 2008.

World Bank Group. ( 2007). Oil Producing Countries, Companies Can Help Mitigate Impact of Climate Change by Reducing Gas Flaring [online], Available internet: www.worldbank.org/ggfr Accessed on 23 July 2008.

World Bank Group. (2008). Global Gas Flaring Reduction [online], Available internet: http://go.worldbank.org/NEBP6PEHS0, Assessed on: 26 August 2008.

Wu, C. (1983). Are your flare systems adequate?,Chemical Engineering, Vol 31 (October), pp. 41-44. 